\title{
Implementation of IoT Enabled Patient Assisting Device-Medibox
}

\author{
Abdul Azeem $\mathrm{K}^{1}$, Ajay $\mathrm{M}^{2}$, Vengetesh $\mathrm{M}^{3}$ \& Dr.G.Saravanavenkatesh ${ }^{4}$ \\ ${ }^{1-3}$ Student, ${ }^{4}$ Professor, Department of EEE, PMIST Deemed to be University, Tamilnadu, India.
}

Copyright: $\odot 2021$ Abdul Azeem K et al. This is an open access article distributed under the terms of the Creative Commons Attribution License, which permits unrestricted use, distribution, and reproduction in any medium, provided the original author and source are credited.

IoT is making strong inroads in the medical industry with the introduction of relevant sensors and devices. IOMT is a collection of medical devices connected to healthcare IT systems for different applications. The growth of IOMT has particularly impacted healthcare for the aged and disabled people, but not just limited to them. In the fast-paced world, even ordinary persons need support with their daily activities. One such important activity is to help them to take their medications daily without missing any dose. The presently available devices for medication adherence have some drawbacks and are restricted to basic functionality like serving only a single purpose of a reminder system. The complexity and cost associated with more elaborate systems led to the development of a new portable device in this paper named "MEDIBOX"- an intelligent medication dispensing device. It is designed to help elderly people who often forget to take their medications or take the wrong pills or dosage. It also helps people who used to travel frequently and are supposed to take regular medication. Hence, we proposed a multi-purpose, portable IoT enabled MEDIBOX which is used purposely to address those pertinent issues. Only about 50 percent of patients adhere to their medication regimen well enough to receive the full benefits of their prescriptions. There are many reasons for not strictly following the regimen i.e., forgetfulness, complexity, lack of proper awareness about the medications, a lack of involvement from family and friends, and so on. Many people cannot remember whether they took their medicine on time, especially those who take multiple drugs. Those who delay their dosage timings run the risk of an overdose when medicating at the nex scheduled time. Under and over-dosage of medicine, the absence of medication administration and monitoring mechanisms can lead to many complexities in health. Although errors can occur in any stages of the medication process, it often happens during the administration stage. MEDIBOX is designed to alert the patient at the right times along with the right dosage in prescription. Along with reminding a patient about medication, it should be ensured that drugs are consumed without degrading their potency. Storage is an important aspect of the total drug control system, so in the design of MEDIBOX an appropriate environment is created to maintain the drug efficacy. The history of medications a person consumed is very important, so the consumption details are uploaded to the cloud for further medical reference. MEDIBOX is also capable enough to alert its user about their next appointment with the doctor. Ambient Assisted Living (AAL) encompasses technical systems to support elderly individuals in their daily activities to allow an independent and safe lifestyle as long as possible. MEDIBOX is focused on assisting the elderly and patients in adhering to the medications regularly without fail, thus helping them to avoid any future difficulties. The details of the consumed medicines with a specific time interval are saved on a secure cloud that can be used for further analysis. Hence in this paper, we have designed a healthcare system that, through the use of IoT-enabled sensors and relevant hardware, assists individuals in taking their prescribed medicines on time avoiding future consequences.

\section{Introduction}

Human life expectancy has been enhanced due to advances in medicine. Even, the diseases that were thought to be incurable can now be treated effectively by one or more drugs. In most cases, patients have to take drugs one or more times a day and they forget to take the drug. Most medicines does have to be taken at a regular interval or for certain times of the day. In this field, the patients sometimes forget to take it and as a result, the expected remedy becomes hard. The problem becomes acute for the patient of elderly people or patients with inadequate skills or knowledge to follow medicine or cognitively impaired patients. This may be explained in further sections.

\section{Hardware Description}

\subsection{ECG Sensors}

The electrocardiogram is a reflection of the electrical activity of heart. The ECG is a quasi-periodically rhythmically repeating signal synchronized by the function of the heart, which acts as a generator of bio- electric events. The potentials originating in the individual fibers of the heart muscles are added to produce the ECG waveform. This generated signal can be described by means of a simple electric dipole consisting of a pair of a positive and negative charge. The dipole generates a field vector, changing nearly periodically in time and space 


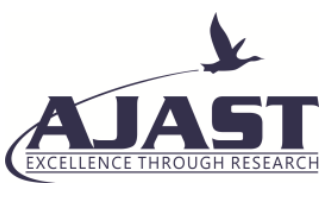

Asian Journal of Applied Science and Technology (AJAST)

Volume 5, Issue 1, Pages 139-142, January-March 2021

and its effects are measured on the surface. Thus an ECG reflects the rhythmic electrical depolarization and Repolarisation of the myocardium (heart muscle) associated with the contraction of the atria and ventricles. The shape, time interval and amplitude of the ECG give the details of state of the heart.

Any form of arrhythmia (disturbance in heart rhythm) can be easily diagnosed using the electrocardiogram. The heart is unique among the muscles of the body in that it possesses the property of automatic rhythmic contraction. The impulses necessary to maintain the pulsation arise from a specified location interior to the heart. The heartbeat is a spontaneous, periodic, electrical potential originating in a small area of the heart muscle tissue, the sinoartrial node. The fundamental beat generated in a S.A node first travels through the heart muscle of artria, causing them to simultaneously contract. The electric wave then travel to the atrio ventricular node, which permits transmission of the contraction of muscle fibres throughout the myocardium. The impulse formation and conduction also produces weak electric currents conducted to the body surface, from where this can be measured by connecting electrodes, because they travel through the body which is an infinite homogenous conductor. The ECG recorded as a differential sum of the outputs of the various electrodes placed at different location in the body.

\subsubsection{ECG Lead Configurations}

To record an electrocardiogram, a number of electrodes, usually twelve are affixed to the body of the patient. These leads are placed in three standardized electrode position.

(1) Bipolar limb leads or standard leads, (2) Augmented unipolar limb leads, (3) Chest leads or precordial leads.

\subsection{Block Diagram}

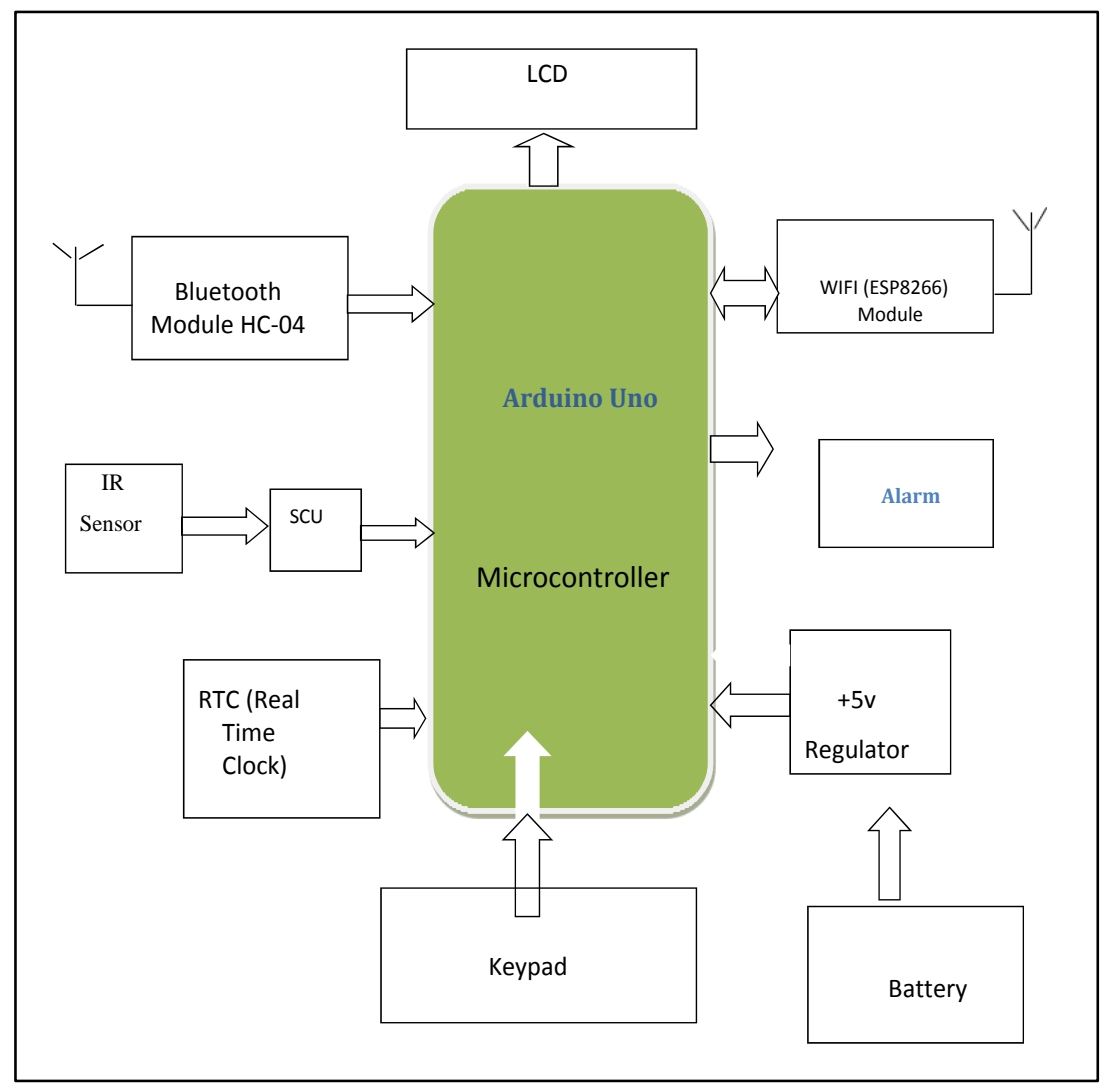

Fig.1. Block Diagram 
The protection against the faults provided in this circuit is as follows,

* Temperature Measurement.

* Heart Beat Measurement.

* ECG Circuit.

* Real Time Clock.

* Infrared Sensor.

\subsection{Software Description Arduino}

Writing sketches, File, Edit, Sketch, Tools, Help, Sketchbook, Tabs, multiple files and compilation, Uploading, Libraries, Third-party hardware, Serial monitor, Preferences, Language support, Boards.

The Arduino Integrated Development Environment - or Arduino Software (IDE) - contains a text editor for writing code, a message area, a text console, a toolbar with buttons for common functions and a series of menus. It connects to the Arduino and Genuine hardware to upload programs and communicate with them.

\section{Results \& Discussions}

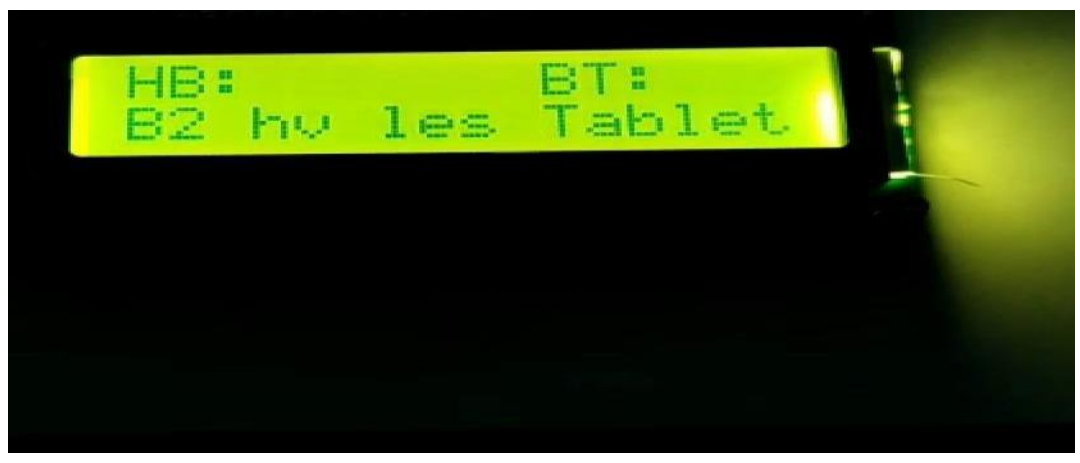

Fig.2. Output Snapshot 1

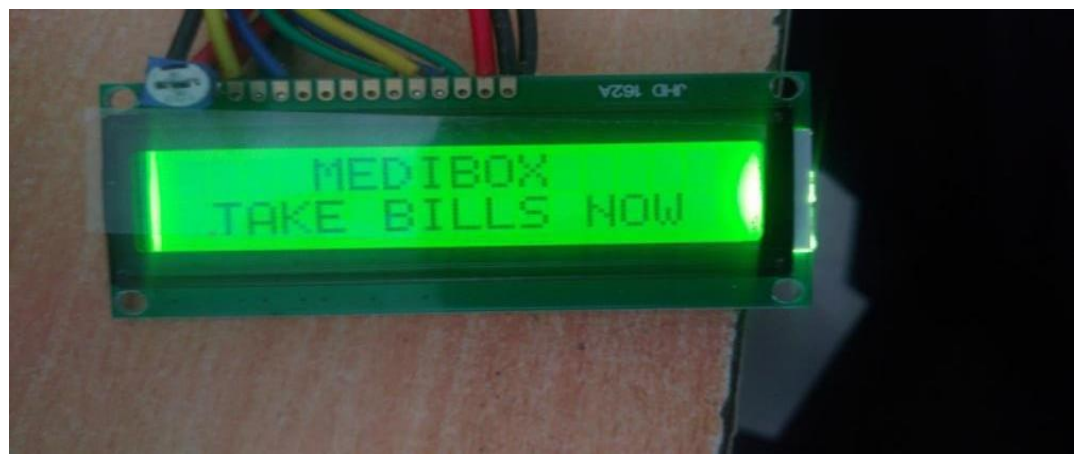

Fig.3. Output Snapshot 2

The above image shows the output of the medibox-IoT enabled patient assisting devices. The output displays the quantity of tablets available and in case of fewer tablets it provides an alert intimating the less tablet on the display with an audio warning. We can also set two sets of alarm for consuming the tablet at the particular time (by using external keyboard). 


\section{AJAST}

Asian Journal of Applied Science and Technology (AJAST)

Volume 5, Issue 1, Pages 139-142, January-March 2021

\section{Conclusions}

In today's scenario, people are busy with their daily schedules and cannot remember their medication timings, which puts them in a difficult condition. In this paper, we have designed a new device MEDIBOX which aims at assisting a patient completely with a compact and user- friendly manner. It reminds the patient to consume the medications and provides a suitable storage condition for the drugs. Storage of medications intake details can assist the doctor for future references i.e. the effectiveness of drugs on the patient can be found through the history of medication intake helping him to prescribe accordingly to the patient.

\section{Declarations \\ Source of Funding \\ This research did not receive any specific grant from funding agencies in the public, commercial, or not-for-profit sectors.}

\section{Competing Interests Statement}

The authors declare no competing financial, professional and personal interests.

\section{Consent to participate}

Not Applicable

\section{Consent for publication}

We declare that we consented for the publication of this research work.

\section{Availability of data and material}

Authors are willing to share data and material according to the relevant needs.

\section{References}

[1] Marie T. Brown, MD and Jennifer K. Bussell, MD, "Medication Adherence: WHO Cares?", Mayo Clin Proc. 2011 Apr; 86(4): 304314doi: 10.4065/mcp.2010.0575.

[2] Cramer JA, Mattson RH, Prevey ML, Scheyer RD, Ouellette VL, "How often is medication taken as prescribed? A novel assessment technique”, Erratum in JAMA 1989 Sep 15; 262(11): 1472.

[3] Machine Ying-Wen Bai and Ting-Hsuan Kuo, "Medication Adherence by Using a Hybrid Automatic Reminder" IEEE International Conference on Consumer Electronics (ICCE), Las Vegas, USA, 2016.

[4] John K. Zao ; Mei-Ying Wang ; Peihsuan Tsai ; Jane W.S. Liu, "Smart phone based medicine in-take scheduler, reminder and monitor" 12th IEEE International Conference on E-Health Networking Applications and Services (Healthcom), 2010.

[5] Deepti Ameta, Kalpana Mudaliar , Palak Patel , "Medication Reminder And Healthcare-An Android Application", International Journal of Managing Public Sector Information and Communication Technologies (IJMPICT) Vol. 6, No. 2, June 2015 DOI : 10.5121/ijmpict.2015.6204 39. 